\title{
Research on the Resonance Analysis of Clustered Grid-connected Distributed Photovoltaic System based on the Wavelet Decomposition
}

\author{
Jing $\mathrm{GaO}^{1, \mathrm{a}}$, Peng $\mathrm{Li}^{1, \mathrm{~b}}$, Jian Sun ${ }^{2, \mathrm{c}}$, Cunping Wang ${ }^{2}$, Hang $\mathrm{Yu}^{1}$ \\ ${ }^{1}$ State Key Laboratory of Alternate Electrical Power System with Renewable Energy Sources, \\ North China Electric Power University, Baoding, 071003, China \\ ${ }^{2}$ State Grid Beijing Electric Power Research Institute, Beijing 100031, China \\ aemail: gjlw912@163.com, bemail: ncepulp@gmail.com, cemail: sunjian04@mails.tsinghua.edu.cn
}

Keywords: Clustered Grid-connected, Distributed photovoltaic, Resonance Analysis, Wavelet Decomposition

\begin{abstract}
The coupling interaction between multiple grid-connected inverters, inverters and grid in the clustered grid-connected distributed photovoltaic (PV) system can cause series and parallel harmonic resonance in the grid. The power quality of grid is seriously affected. Therefore, the resonance problem of the clustered grid-connected distributed PV is urgent to be studied. Aiming at this problem, a resonance analysis model of clustered grid-connected distributed PV system is established in this paper. Besides, the resonance problem of clustered grid-connected distributed PV system during its operation is analyzed. Moreover, a fast resonance detection method based on Wavelet Decomposition is proposed. Finally, simulations verify the effectiveness of the proposed method for the resonance problem of the clustered grid-connected distributed PV system.
\end{abstract}

\section{Introduction}

In recent years, the global energy crisis and environmental problems have become increasingly serious. Renewable energy such as photovoltaic (PV) is getting more and more attention. PV grid-connected system is becoming more widely used with the continuous reduction of the cost of PV cells [1]. In distribution network, the types of distributed generations and nonlinear wavy loads are complex. Particularly, the output power of wind turbines and PV cells is fluctuant, random, and intermittent, which often leads to the power unbalance between source and load in the distribution network. In addition, a large number of harmonics and inter harmonics are generated because of extensive application of a large amount of electric power electronic equipments. As mentioned above, resonance and other power quality problems are becoming more complex and prominent in the distribution network $[2,3]$. Therefore, the research of resonance in the clustered grid-connected distributed PV system has important theoretical value and urgent practical significance.

Distributed PV sources are connected to distribution network via inverters, which may cause multiple power quality problems in the grid, such as voltage and current harmonics, voltage sag, voltage swell, voltage interruption, voltage fluctuation and flicker, voltage and current imbalanced component and resonance. A large number of distributed PVs are connected in the distribution network, so the harmonic and resonance of the distribution network must have various spectrums. At the same time, the voltage fluctuation and flicker signal in the network are random and dynamic non-stationary signals [4]. As for resonance disturbance detection of clustered grid-connected distributed PV system, it is needed to propose a detection method to analyze not only the harmonic and resonance signal, but also the nonlinear and non-stationary signals.

The closed-loop control of both voltage-source converter (VSC) and current-source converter (CSC) systems with LC filters is investigated in [5], with a focus being put on the damping of LC resonance. Paper [6] designs a virtual harmonic resistance based active damping method to mitigate the resonances. And paper [7] presents that compared with traditional Fourier transform and short-time Fourier transform (STFT), the Wavelet Decomposition has the time-frequency local characteristic and it is adaptive. Therefore, the Wavelet Decomposition method is suitable for the resonance disturbance detection of clustered grid-connected distributed PV system. 
In this paper, a simple introduction of the clustered grid-connected distributed PV system is presented. Application principle of Wavelet Decomposition in the clustered grid-connected distributed PV system is briefly introduced. Wavelet Decomposition algorithm is used to detect and analyze the resonant voltage and resonant current problem in the clustered grid-connected distributed PV system. Simulations are carried out in MATLAB/ SIMULINK.

\section{Resonance Analysis of Clustered Grid-connected Distributed PV System}

\section{A. Structure of clustered grid-connected distributed PV system}

Fig.1 shows the grid-connected PV power generation system. Grid-connected distributed PV units or distributed generations $n$ are connected to the point of common coupling (PCC) through the line $i$. And it is connected to the distribution network whose internal impedance is $Z_{g}[8]$.

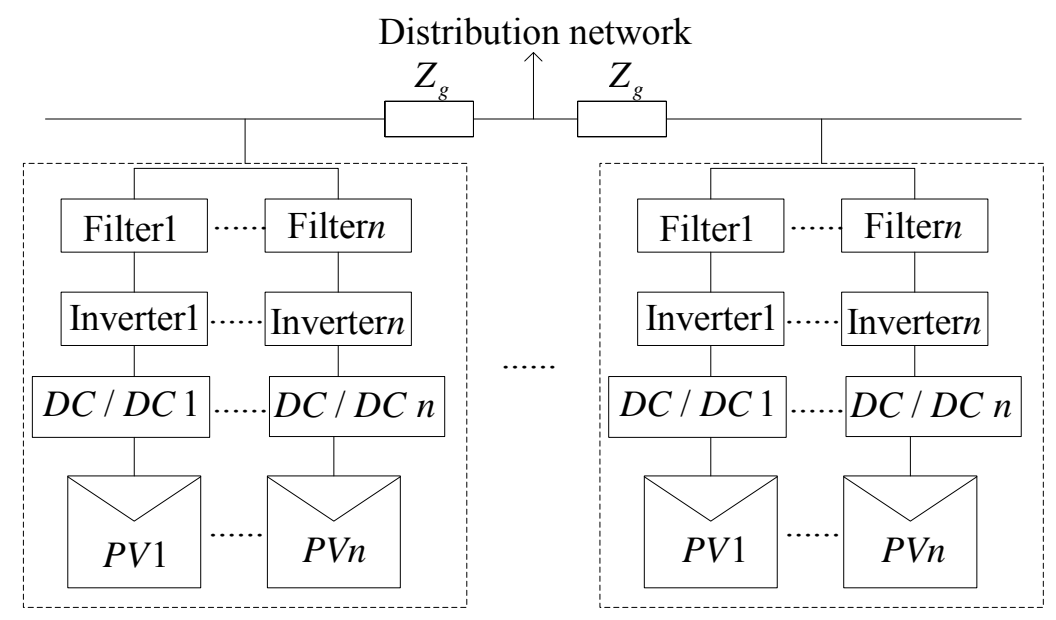

Distributed PV cluster network1 Distributed PV cluster network $n$

Fig.1. Typical grid-connected PV power generation system

The structure of clustered grid-connected distributed PV system is shown in Fig.2, including the PV array, a DC-DC converter, an inverter, filter devices, and the equivalent grid. Ignoring the influence of the grid impedance and the external disturbance, the control block diagram of clustered grid-connected distributed PV inverter is shown in Fig. 3. And $i_{g}$ is the inverter current, $i^{*}$ is the reference current, $u_{g}$ is the grid voltage.

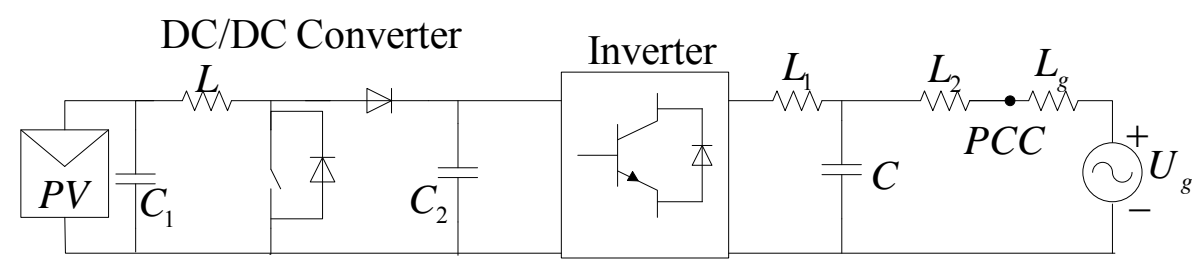

Fig.2. Structure of clustered grid-connected distributed PV system 


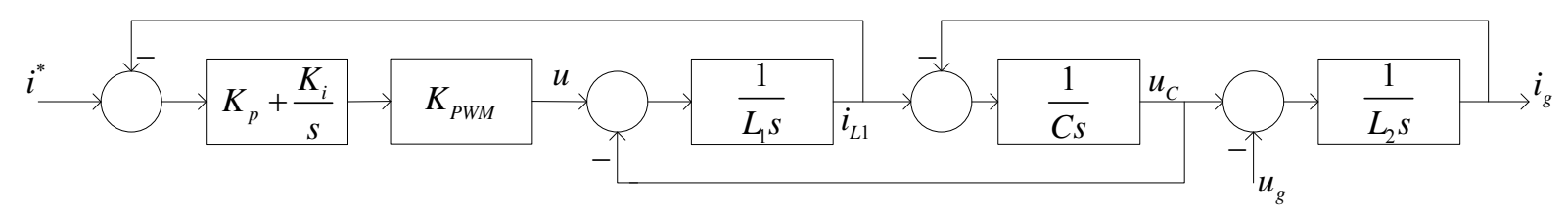

Fig.3. Control block diagram of clustered grid-connected distributed PV inverter

The transfer function of the grid-connected current $i_{g}$ and reference current $i^{*}$ can be obtained by the Mason formula as follows:

$$
\begin{aligned}
G(s)=\frac{i_{g}}{i^{*}}= & {\left[K_{P W M}\left(K_{p}+\frac{K_{i}}{s}\right) \frac{1}{s L_{1}+R_{1}} \frac{1}{s C} \frac{1}{s L_{2}+R_{2}}\right] /\left[1+K_{P W M}\left(K_{p}+\frac{K_{i}}{s}\right) \frac{1}{s L_{1}+R_{1}}\right.} \\
& \left.+\frac{1}{s L_{1}+R_{1}} \frac{1}{s C}+\frac{1}{s C} \frac{1}{s L_{2}+R_{2}}+K_{P W M}\left(K_{p}+\frac{K_{i}}{s}\right) \frac{1}{s L_{1}+R_{1}} \frac{1}{s C} \cdot \frac{1}{s L_{2}+R_{2}}\right]
\end{aligned}
$$

Among them, $K_{P W M}$ is $P W M$ gain, $K_{p}+\frac{K_{i}}{S}$ is $P I$ controller parameters.

\section{B. Analysis of inherent resonance frequency of LCL network}

Fig.4 (a) is a structure diagram of the LCL network, which can be equivalent to the equivalent circuit model of LCL resonant analysis as shown in Fig.4 (b).

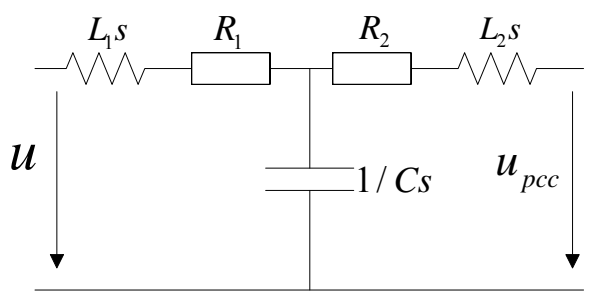

(a) $L C L$ network structure

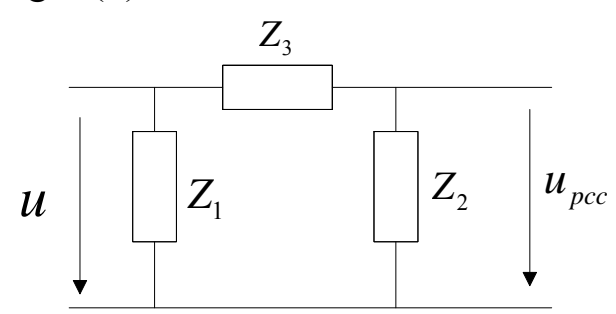

(b) $L C L$ resonance analysis circuit

Fig.4. Resonance analysis model of LCL filter network

From Fig.4 (a) and (b), the impedances of the series and parallel resonant circuit are respectively:

$$
\begin{gathered}
Z_{1}(s)=L_{1} s+R_{1}+\left(1+\frac{L_{1}}{L_{2}}\right) \frac{1}{C s} \\
Z_{2}(s)=L_{2} s+R_{2}+\left(1+\frac{L_{2}}{L_{1}}\right) \frac{1}{C s} \\
Z_{3}(s)=\left(L_{1}+L_{2}\right) s+R_{1}+R_{2}+\left(L_{1} s+R_{1}\right)\left(L_{2} s+R_{2}\right) C s
\end{gathered}
$$

Among them, $Z_{1}$ and $Z_{2}$ constitute a typical series resonant circuit, and the $Z_{3}$ can be regarded as the parallel resonance circuit. The series and parallel impedance branch respectively exist in the series and parallel resonant points. And the resonance frequencies are respectively:

$$
\begin{gathered}
w_{1}=w_{2}=w_{3}=\sqrt{\frac{L_{1}+L_{2}}{L_{1} L_{2} C}} \\
f_{1,2,3}=w_{1,2,3} / 2 \pi
\end{gathered}
$$

In the case of ignoring the damping factor, series and parallel resonant frequencies are equal, that is $w_{1}=w_{2}=w_{3}$. Taking into account the grid impedance, $L_{2}$ is replaced by $L_{2}+L_{g}$. And taking the system parameters shown in Table 1 into the formula (5) and (6), inherent resonance frequency which equals $988.45 \mathrm{~Hz}$ can be obtained. 
Table1. Parameters of clustered grid-connected distributed PV system

\begin{tabular}{c|l|l|l}
\hline \multicolumn{1}{c|}{ Parameters } & Value & \multicolumn{1}{|c|}{ Parameters } & Value \\
\hline Filter inductance $L_{1} / m H$ & 2 & Filter capacitor $C_{1} / \mu F$ & 50 \\
Filter inductance $L_{2} / m H$ & 0.5 & Grid frequency $f / H z$ & 50 \\
Filter resistance $R_{1} / \Omega$ & 0.001 & Sampling frequency $f_{C} / \mathrm{kHz}$ & 10 \\
Filter resistance $R_{2} / \Omega$ & 0.1 & Grid equivalent inductance $L_{g} / \Omega$ & 0.2 \\
& & Grid equivalent resistance $R_{g} / \Omega$ & 0.05 \\
\hline
\end{tabular}

\section{Application of Wavelet Decomposition in Clustered Grid-connected Distributed PV System}

\section{A. Wavelet analysis and its characteristics}

Wavelet Decomposition is analysis method for signals of time-scale (time-frequency), and has characteristic of multi resolution analysis. And in time domain and frequency domain it can describe the local characteristic of signals. It is a time-frequency localization analysis method whose window size is fixed and shape can be changed. In the low frequency part, it has higher frequency resolution and lower time resolution, while it has higher time resolution and lower frequency resolution in the high frequency part. Therefore, it is very suitable for the detection of resonance signals [9].

This paper uses one-dimensional discrete wavelet transform. Selection of an appropriate wavelet function is very important. The more similar the wavelet waveform and signal waveform are, the better the decomposition effect can be obtained [10]. Because the $\mathrm{db}$ wavelet is sensitive to irregular signals and has the characteristics of compact support and orthogonality, the $\mathrm{db} 4$ wavelet is used to decompose the resonance signals in clustered grid-connected distributed PV system.

\section{B. Principle of detecting resonance based on wavelet transform}

In wavelet analysis process, the key is selecting wavelet function and determining the number of decomposition level. Resonance is random signal in the clustered grid-connected distributed PV system. And currently the $\mathrm{db} 4$ wavelet base function is more widely used in non-stationary vibration signal analysis. As for resonance signals in clustered grid-connected distributed PV system, this paper uses db4 wavelet function to decompose them, then decomposition levels need to be chosen based on the signal sampling frequency and the resonant frequency [11].

If it is assumed that the resonant signal sampling frequency is $f_{1}$ and the inherent resonance frequency is $f_{2}$, according to the theory of wavelet analysis and the sampling theorem, the band range of scale $n$ low frequency coefficients is $0 \sim \frac{f_{1} / 2}{2^{n}}$ when resonance signal is decomposed at a level of $n$ in clustered grid-connected distributed PV system. In order to make the low frequency part of the wavelet decomposition not contain resonant noise components, scale $n$ must satisfy [12]:

$$
\frac{f_{1} / 2}{2^{n}} \leq f_{2}
$$

In this paper, sampling frequency of the actual resonant signals in clustered grid-connected distributed PV system is $10000 \mathrm{~Hz}$. And the effective frequency of the resonant signal is $988.45 \mathrm{~Hz}$. According to (7), the reasonable wavelet decomposition number is 3. 


\section{Resonance Detection of Clustered Grid-connected Distributed PV System based on Wavelet Analysis Method}

In order to verify the above analysis, simulation model of clustered grid-connected distributed PV system is built in MATLAB/SIMULINK. And program of the Wavelet Decomposition method for analyzing resonant signal is performed. Specific parameters are shown in Table 1

A. Resonant analysis of single grid-connected inverter

A clustered grid-connected distributed PV demonstration project is taken as a simulation example, and the grid-connected resonant current $I_{g 1}$ waveforms of a single inverter and the waveforms of db4 wavelet analysis are shown in Fig.5. Among them the grid frequency $f_{0}=50 \mathrm{~Hz}$, sampling frequency $f_{s}=10000 \mathrm{~Hz}$, the length of sampling points is 2000 points. It is shown that cd 3 energy is the most concentrated with the frequency band $[625 \mathrm{~Hz}, 1250 \mathrm{~Hz}]$, and it is correspond to the inherent resonant frequency $987.5 \mathrm{~Hz}$. Therefore, the wavelet analysis method can accurately detect the single inverter grid-connected resonant current.

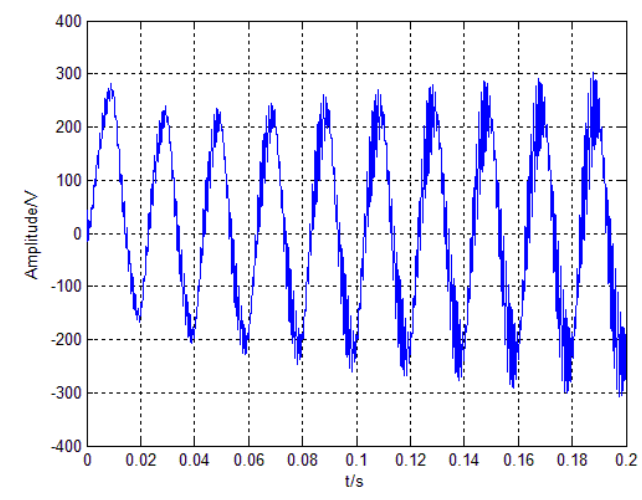

(a) Grid-connected resonant current waveform
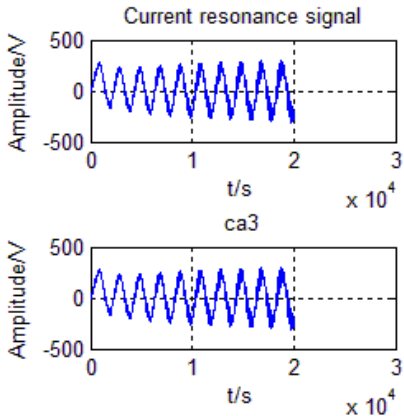

$\mathrm{cd} 2$

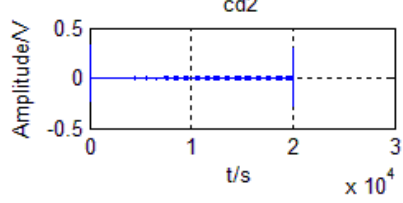

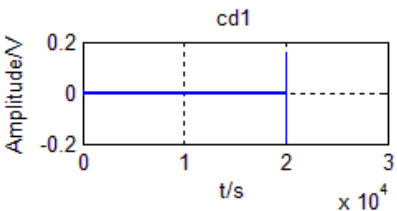

$\mathrm{cd} 3$

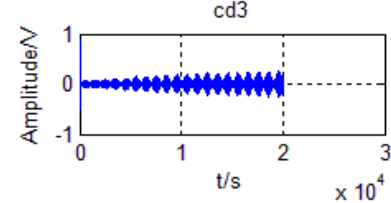

(b) Wavelet analysis waveform

Fig.5. Wavelet analysis waveform of the grid-connected resonant current of a single inverter

\section{B. Resonant analysis of two grid-connected inverters}

Taking a demonstration project as an example, the grid-connected resonant current $I_{g 2}$ waveforms of two inverters and the waveforms of $\mathrm{db} 4$ wavelet analysis are shown in Fig.6. It is shown that cd3 energy is the most concentrated with the frequency band $[625 \mathrm{~Hz}, 1250 \mathrm{~Hz}]$, and it is correspond to the inherent resonant frequency $988.89 \mathrm{~Hz}$. Therefore, the wavelet analysis method can accurately detect the two inverters grid-connected resonant current. 


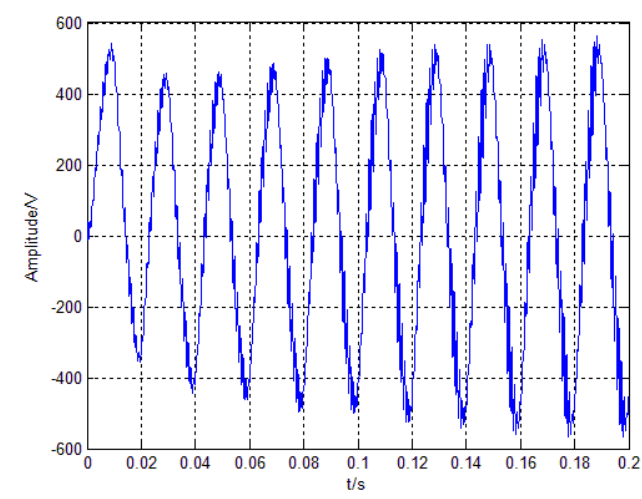

(a) Grid-connected resonant current waveform
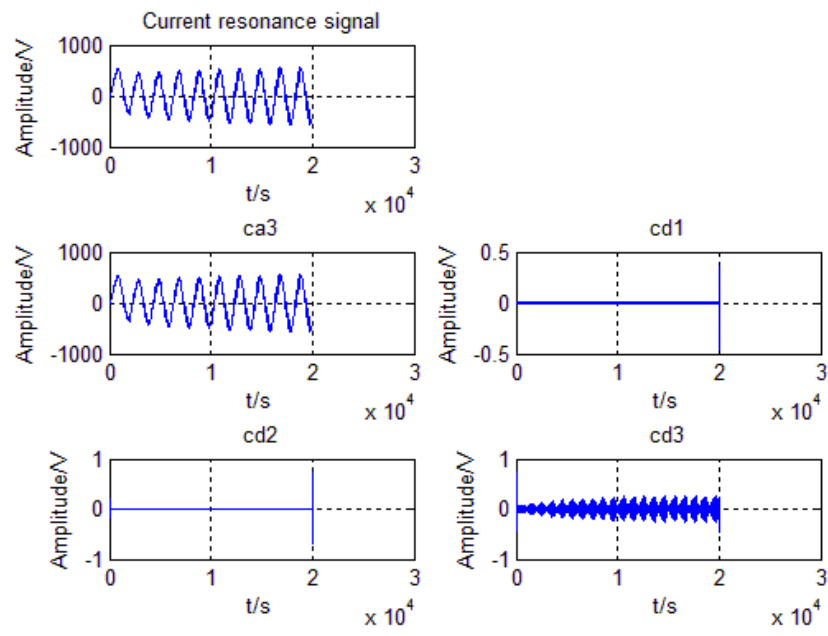

(b) Wavelet analysis waveform

Fig.6. Wavelet analysis waveform of the grid-connected resonant current of two inverters

Simulation results show that in the analysis of resonance signal of clustered grid-connected distributed PV system process, db4 wavelet is more appropriate. Decomposition level is determined by (7), and ideal results are obtained. Namely, the simulation verifies that Wavelet Decomposition algorithm can accurately detect resonance signals in the clustered grid-connected distributed PV system.

\section{Conclusion}

In this paper, the resonance analysis model of clustered grid-connected distributed PV system is established with typical distributed PV clustered structure. The resonance problem of the PV clustered operation is analyzed. Wavelet Decomposition algorithm is used to detect and analyze the resonance problem of single grid-connected inverter and two grid-connected inverters in clustered grid-connected distributed PV system. Simulation results demonstrate that the wavelet analysis method can effectively detect the resonance problem in clustered grid-connected distributed PV system. The proposed method can effectively detect resonance signals disturbance of power system, provide good environment for grid-connected clustered distributed generations, and improve the reliability of power supply.

\section{Acknowledgement}

In this paper, the research was sponsored by the Research on Key Technologies of Operation and Control for Distributed Photovoltaic Cluster (Project No. 520201150012) and the National Natural Science Foundation of China (Project No. 50977029).

\section{References}

[1] J. L. Agorreta, M. Borrega, and J. Lo'pez, "Modeling and control of $\mathrm{n}$-paralleled grid-connected inverters with LCL filter coupled due to grid impedance in PV plants," IEEE Trans. Power Electronics, 2011, 26(3): 770-785.

[2] M. Castilla, J. Miret, J. Matas, L. G. de Vicuña, J. M. Guerrero, "Linear current control scheme with series resonant harmonic compensator for single-phase grid-connected photovoltaic inverters," IEEE Trans. Industrial Electronics, 2008,55(7): 2724-2733.

[3] N. Mutoh and T. Inoue, "A control method to charge series-connected ultraelectric double-layers capacitors suitable for photovoltaic generation systems combining MPPT control method,” IEEE Trans. Industrial Electronics, 2007, 54(1): 374-383 
[4] T. Tayjasanant, W. C. Wang, C. Li, et al, "Inter-harmonic flicker curves, IEEE Trans. Power Delivery", 2005,20(2): 1017-2000.

[5] Y. W. Li, "Control and resonance damping of voltage source and current source converters with LC Filters,” IEEE Trans. Industrial Electronics, 2009, 56(5): 1511-1521.

[6] J. He, Y. W. Li, D. Bosnjak, and B. Harris, "Investigation and active damping of multiple resonances in a parallel-inverter-based microgrid," IEEE Trans. Power Electronics, 2013, 28(1): 234-246.

[7] S. Santoso, W. M. Grady, E. J. Powers, et al, "Characterization of distribution power quality events with Fourier and wavelet transforms," IEEE Journals \& Magazines, 2000,15(1): 247-254.

[8] Y. Xue, L. Chang, S. B. Kjaer, J. Bordonau, and T. Shimizu, "Topologies of single-phase inverters for small distributed power generators: An overview," IEEE Trans. Power Electronics, 2004, 19(5): 1305-1314.

[9] A. Pigazo, M. Liserre, R. A. Mastromauro, V. M. Moreno, A. Dell'Aquila, "Wavelet-based islanding detection in grid-connected PV systems," IEEE Trans. Industrial Electronics, 56(11): 4445-4455.

[10] S. Yilmaz and Y. Oysal, "Fuzzy wavelet neural network models for prediction and identification of dynamical systems," IEEE Trans. Neural Networks and Learning Systems, 2010, 21(10): 1599-1609.

[11] Y. H. Gu, M. H. J. Bollen, "Time-frequency and time-scale domain analysis of voltage disturbances,” IEEE Trans. Power Delivery, 2000, 15(4): 1279-1284.

[12] B. Julio, D. Ramon, "Application of the wavelet-packet transform to the estimation of harmonic Groups in Current and Voltage waveforms," IEEE Trans. Power Delivery, 2006, 21(1): 533-535. 